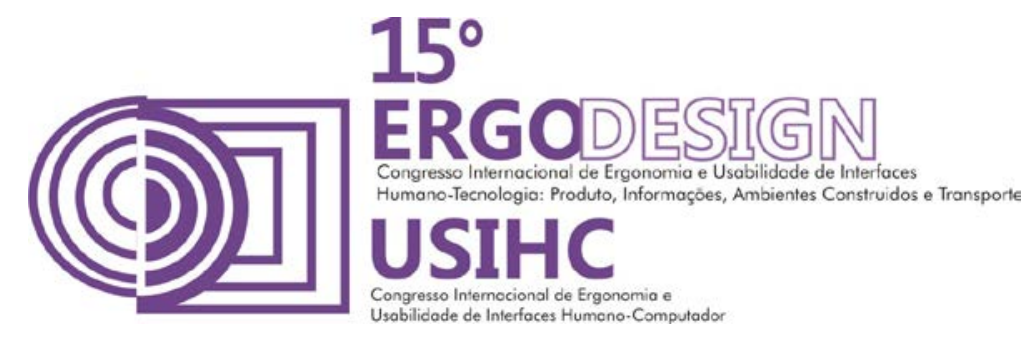

\title{
ANÁLISE POSTURAL NA PÓS-COLHEITA DA BANANA: ETAPA DE DESPENCAMENTO
}

\section{POSTURAL ANALYSIS AT THE BANANA POSTHARVEST: SEPARATING BANANA BUNCHES FROM THE STALK}

\author{
TAKAYAMA, Letícia (1); \\ MERINO, Eugenio Andres Diaz (2); \\ MERINO, Giselle Schmidt Alves Diaz (3).
}

(1) Universidade Federal de Santa Catarina, Graduanda

e-mail:takayamaleticia@gmail.com

(2) Universidade Federal de Santa Catarina, Doutor

e-mail: eugenio.merino@ufsc.br

(3) Universidade Federal de Santa Catarina, Doutora

e-mail: gisellemerino@gmail.com

\begin{abstract}
RESUMO
O presente estudo investiga os constrangimentos posturais na tarefa de despenca dos cachos de bananas, etapa que ocorre na pós-colheita. A coleta de dados ocorreu com base em observações diretas de vídeos feitos em uma produtora de bananas da região de Corupá-SC. A análise dos dados baseou-se no sistema OWAS de registro postural. O resultado desta pesquisa visa a melhoria ergonômica da ferramenta manual utilizada para o corte das pencas e, consequentemente, a redução dos danos à saúde do trabalhador.

Palavras-chave: bananicultura, ferramenta manual ergonômica, constrangimento postural, OWAS
\end{abstract}

\begin{abstract}
The present study investigates the postural constrains in separating bananas bunches from the stalk, step that occurs in post-harvest. The data collected were based on direct observations of videos at a banana producer in Corupá-SC. The data analysis were based on OWAS posture analysis system. The result of this research aims to improve ergonomics in the hand tool used for cutting the banana bunches and reduce the damage to worker's health.

Keywords: banana postharvest, ergonomic hand tool, postural constraint, OWAS
\end{abstract}




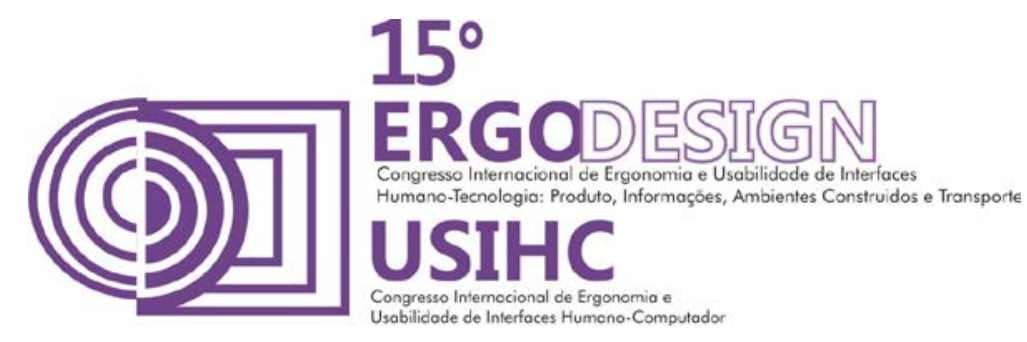

\section{INTRODUÇÃO}

A ergonomia tem o papel de contribuir para a avaliação de tarefas, ferramentas, sistemas e ambientes de trabalhos a fim de torna-los compatíveis com as necessidades, habilidades e limitações das pessoas (IEA, 2000). A aplicação da ergonomia na agricultura é recente, em comparação com a usada na indústria, por ser considerada uma atividade não estruturada. $O$ trabalho realizado por agricultores geralmente é árduo e ocasiona posturas inconvenientes, forças musculares excessivas, uso repetitivo de equipamentos e condições ambientais desfavoráveis (IIDA, 2005). Uma grande parte das lesões na agricultura é devido aos riscos no ambiente de trabalho, pelos equipamentos utilizados e as condições adversas da atividade (MONTEIRO, 2004). A atividade agrícola também demanda cargas de trabalho que podem prejudicar o organismo do trabalhador e causar problemas de saúde corporal devido ao desgaste físico e aumento do índice de erro. Um dos principais problemas de trabalhadores agrícolas está relacionado com a má postura e utilização equivocada de ferramentas e equipamentos, o que tendem a causar dor lombar, fadiga, acidentes e doenças ocupacionais, que podem gerar problemas crônicos agudos (FLEMING, 2003).

Medidas ergonômicas aplicadas nos postos de trabalho podem a reduzir as exigências biomecânicas e cognitivas do trabalhador. Alguns exemplos de medidas tomadas para promover o equilibro biomecânico e reduzir os danos à saúde são: eliminação de tarefas muito repetitivas e adaptações de máquinas, equipamentos, ferramentas e materiais (IIDA, 2005).

Em especifico, na produção de banana ainda há uma defasagem nos estudos e aplicações de melhorias ergonômicas para a redução de danos à saúde do trabalhador. Atualmente a bananicultura é um dos principais negócios internacionais nas regiões tropicais e subtropicais do mundo (SILVA NETO; GUIMARÃES, 2011). O Brasil é o quinto maior produtor de banana do mundo, com a produção de 6.902 .184 toneladas em 2012 , o que equivale a $6,8 \%$ da produção mundial (EMBRAPA, 2013).

A banana (Musa spp.) é uma das frutas mais consumidas no mundo e seu cultivo é feito em mais de 130 países. Além do fruto, o coração e o interior do tronco da bananeira são comestíveis e sua fibra pode fabricar tecidos de alta qualidade e papéis (ARAGUAIA, 2014). A banana é uma fruta frágil e exige grandes cuidados tanto na colheita como na pós-colheita, etapas que demandam grande quantidade de força e precisão dos trabalhadores (BORGES et al., 2014).

O presente artigo tem como objetivo a análise dos constrangimentos posturais na tarefa de despenca dos cachos de bananas, etapa que ocorre na pós-colheita, a fim de criar melhorias na ferramenta manual usada no processo e reduzir os danos à saúde do trabalhador. Cabe ressaltar que esta pesquisa faz parte de um estudo para a melhoria ergonômica da ferramenta de corte de separação das pencas de bananas, que não obteve mudanças significativas ao longo dos anos, e possui como características um cabo cilíndrico não ergonômico e uma lâmina longa, estreita e curva em espiral. 


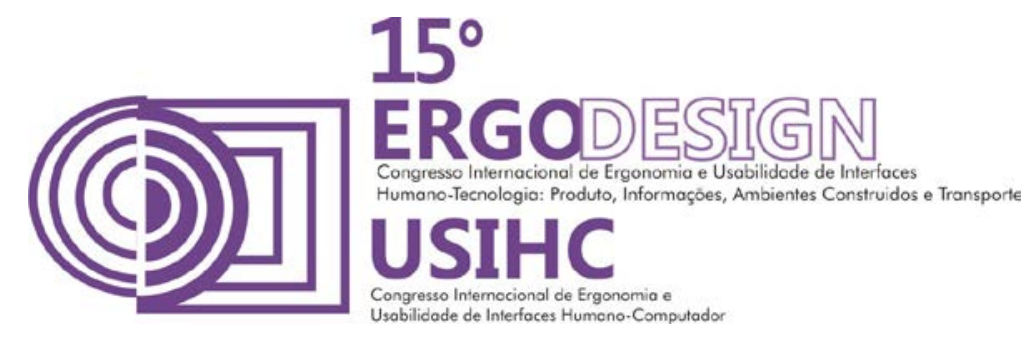

\section{REFERENCIAL TEÓRICO}

\subsection{Pós-colheita da banana}

Para entender melhor a etapa de despenca das bananas, universo em que a pesquisa se aplicou, é necessário ter uma visão das outras etapas do processo de pós-colheita da banana, para compreender a sua trajetória.

Depois e colhido, o cacho de bananas é transportado com cuidado para a casa de embalagem por meio de cabos aéreos, carrinho de mão, carreta ou sobre travesseiros de espuma no ombro do operário. Para evitar danos no cacho (batidas, quedas, pressões e atritos), são adotados cuidados no transporte, como o uso de superfícies de espuma, materiais de proteção e acomodamento suave das pencas em carretas (BORGES et al., 2014).

$\mathrm{Na}$ casa de embalagem, são feitos os processos de despistilagem, despencamento, confecção de buquês, lavação, classificação, pesagem, tratamento antifúngico, colação de selos de qualidade e embalagem da fruta (BORGES et al., 2014).

Os cachos são pendurados por meio de ganchos na sombra após sua chegada à casa. A primeira etapa do processo é a retirada de detritos (frutos não formados, frutos podres, pedaços de folha ou outro material aderido) e despistilagem do cacho (retirada de restos florais nas pontas das bananas) (BORGES et al., 2014).

O despencamento é a retirada das pencas da banana do engaço ${ }^{1}$. Para isto, os cachos de bananas são pendurados pelo engaço por meio de ganchos, para facilitar o corte de separação das pencas, feito rente à ráquis ${ }^{2}$ (BORGES et al., 2014). Cada corte separa apenas uma penca de bananas do engaço, deste modo, este movimento é efetuado repetidas vezes durante a jornada de trabalho, o que aumenta os riscos na saúde do trabalhador.

A ferramenta de despenca analisada (Figura 1) é um modelo amplamente usado na bananicultura brasileira e possui um cabo e uma lâmina longa em espiral, que ajuda no movimento de retirada das frutas. Os cachos das bananas são retirados de cima para baixo por meio da fixação da ferramenta no vão entre as pencas torção da mesma, para o corte da ráquis.

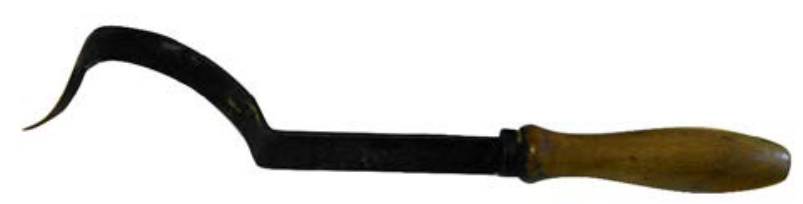

Figura 1: Ferramenta de despenca das bananas

Fonte: Próprios autores

\footnotetext{
1 Pedúnculo de suporte que sustenta o cacho de bananas

${ }^{2}$ Eixo principal comum de união das bananas
} 


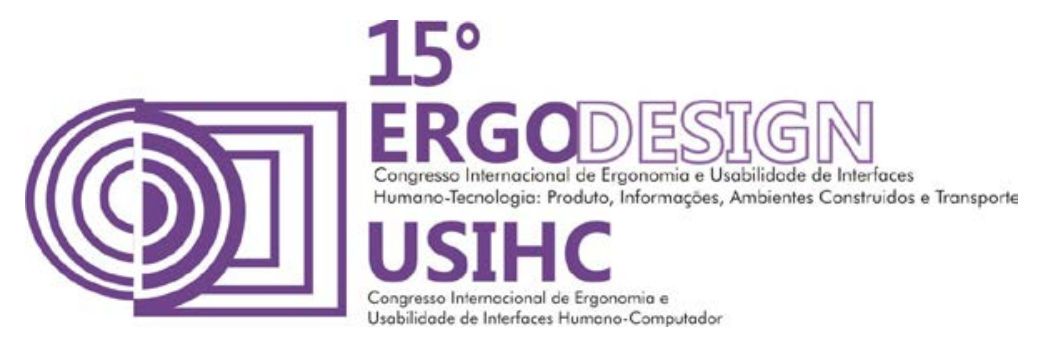

Após o despencamento, as pencas são colocadas em tanques de lavação para retirar impurezas e cicatrizar os cortes. As frutas são retiradas deste tanque e passam para o processo subdivisão, onde cada penca é dividida em buquês compostos de dois a nove bananas unidas, afim de facilitar a embalagem e acondicionamento do produto (BORGES et al., 2014).

Os buquês precisam ser classificados, pesados e etiquetados corretamente, para garantir a qualidade das frutas. Após esta etapa, as frutas são colocadas cuidadosamente em embalagens em forma de caixas de papelão ou de plástico, revestidas internamente com plástico para proteger a fruta de perda excessiva de água ou atritos (BORGES et al., 2014).

\subsection{Manejo da ferramenta de despenca}

O manejo de uma ferramenta é considerado um movimento de controle executado pelo corpo humano a fim de transmitir alguma forma de energia ao objeto. Os manejos podem variar conforme a força, velocidade e precisão graças à grande mobilidade do dedo polegar opositor (IIDA, 2005).

No caso da faca de despencamento, o manejo é grosseiro pois é executado com o centro da mão. Neste caso, os dedos servem para prender a ferramenta e mantêm-se estáticos, enquanto o punho e o braço movimentam-se. O manejo grosseiro, em geral, transmite maiores forças e possui velocidade e precisão menores, comparados ao manejo fino. A força da pega grosseira tipo empunhadura, com todos os dedos fechando-se em volta do objeto, pode chegar a $40 \mathrm{~kg}$ (IIDA, 2005).

Os movimentos feitos durante o uso da ferramenta de despenca são relacionados às articulações do membro superior, em específico: cotovelo, ombro e punho.

\subsection{Biomecânica das articulações do membro superior}

A mão do homem é a ferramenta operadora da extremidade do membro superior e permite a realização de inúmeras funções, graças à preensão (KAPANDJI, 2000). A mão, o punho e os dedos permitem atividades de manipulação por meio de uma grande variedade de posturas. A maioria dos músculos nas articulações do punho, mão e dedos possuem origem no cotovelo, sendo assim, algumas lesões causadas nestas áreas podem se refletir para outras partes do corpo (HAMILL; KNUTZEN, 2012).

A mão possui um grande número de articulações para desempenhar os movimentos. Estas articulações são denominadas de carpometacarpais, intermetacarpais, metacarpofalângica e interfalângica. A articulação carpometacarpal do polegar permite uma grande gama de movimentos, enquando da segunda até a quarta articulação carpometacarpal os movimentos são mais reduzidos pela presença de contenções ligamentares. Os movimentos de flexão, extensão, abdução dos dedos (afastamento dos outros dedos do dedo médio), adução (aproximação dos outros dedos ao dedo médio) e circundação do segundo ao quinto dedo são responsáveios pela articulação metacarpofalângica (HALL, 2009).

A força na mão está associada à força de preensão para segurar objetos. A preensão que produz mais força é aquela feita com o punho cerrado, com flexão de todas as três articulações dos dedos (intermetacarpais, metacarpofalângica e interfalângica). A posição do punho também interfere no aumento da força de preensão, porém aumenta a incidência de tensão e 


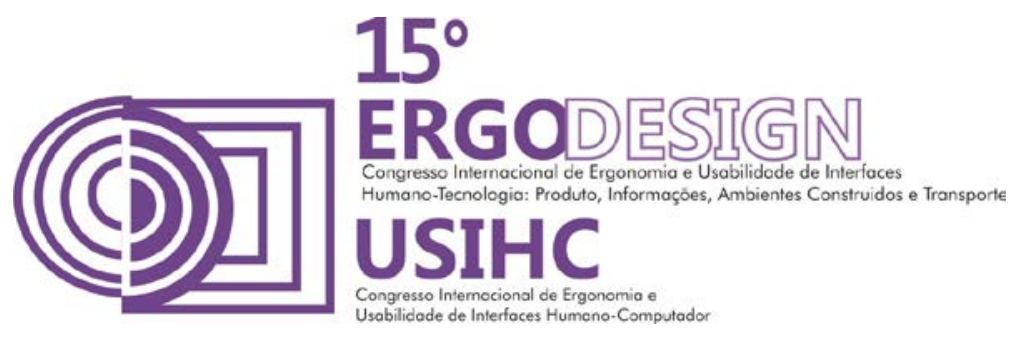

compressão de áreas adjacentes do punho. Sendo assim, a posição neutra do punho é a mais adequada e segura, pela redução de lesões nas estruturas do punho (HAMILL; KNUTZEN, 2012).

O punho é articulação distal do membro superior e guia a mão para uma melhor posição de preensão, por meio de movimentos rotacionais e nos planos sagital e frontal (KAPANDJI, 2000). O movimento rotacional do punho, chamado de circundução, é definido como a combinação dos movimentos de flexão-extensão e abdução-adução. Este movimento se realiza simultaneamente nos dois eixos desta articulação (KAPANDJI, 2000).

A flexão e extensão são movimentos do punho no plano sagital. A flexão corresponde ao movimento da superfície palmar em direção à face anterior do antebraço. Já a extensão é o retorno da mão para a posição neutra, enquanto a extensão é o movimento contrário da flexão, ou seja, a superfície dorsal da mão aproxima-se da face posterior do antebraço (HALL, 2009). Os movimentos de abdução e adução são feitos no plano frontal. A abdução é caracterizada como o movimento da mão em direção ao lado do dedo polegar, enquanto o movimento para 0 lado oposto é denominado de adução (HALL, 2009).

O cotovelo é a articulação intermediária do membro superior e une seu primeiro e segundo segmentos: braço e antebraço. O cotovelo tem como função estender e deslocar mais ou menos longe, nos três planos, a mão que é a extremidade ativa do membro superior. Juntamente com o braço, o cotovelo constitui um compasso que possibilita a aproximação da mão ao ombro e à boca (KAPANDJI, 2000).

Uns dos movimentos efetuados pelo cotovelo são a flexão e extensão. No movimento de flexão, o cotovelo diminui o ângulo entre o braço e o antebraço, já o movimento de extensão é quando ocorre o inverso. O movimento de rotação do antebraço ao redor de seu eixo longitudinal é denominado pronação-supinação. Estes movimentos só são possíveis de análise quando o cotovelo encontra-se flexionado a $90^{\circ}$ rente ao corpo. A posição de supinação do cotovelo se realiza quando a mão está para cima com o polegar para fora, já na posição e pronação a palma da mão está para baixo e o polegar para dentro (KAPANDJI, 2000).

O ombro é considerado a articulação mais móvel do corpo humano, pois possui três eixos principais que permitem orientar o membro superior nos três planos do espalho e são conhecidos como: transverso, ântero-posterior e vertical. O eixo transverso permite os movimentos de flexão (movimento de grande amplitude, $180^{\circ}$, para frente) e extensão (movimento de escassa amplitude, 45 a $50^{\circ}$, para trás) no plano sagital. Já o eixo ânteroposterior permite os movimentos de abdução (afastamento do membro superior do plano de simetria) e adução (aproximação do membro superior do plano de simetria). Por fim, o eixo vertical é determinado pela intersecção do plano frontal e sagital e também possui papel fundamental na flexão-extensão do cotovelo. A rotação do braço ocorre sobre o eixo longitudinal em qualquer posição do ombro.

\section{METODOLOGIA}

Esta pesquisa caracteriza-se como um estudo exploratório com natureza aplicada, a fim de levantar dados qualitativos das posturas de um determinado trabalhador por meio da observação direta documentada em fotos e vídeos utilizando o sistema OWAS. O estudo de campo teve como foco a análise dos movimentos das articulações do membro superior de um 


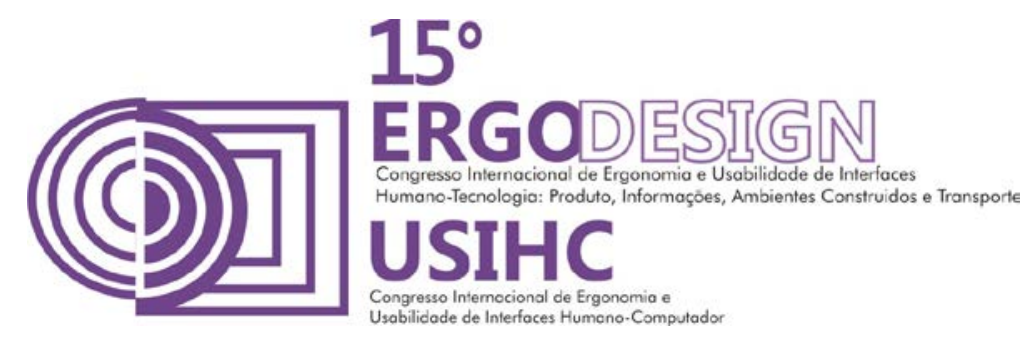

trabalhador da bananicultura na realização da atividade de despenca das bananas do engaço. A pesquisa foi de fundamental importância para obter de informações ainda pouco investigadas sobre os danos causados pelo uso de ferramentas na bananicultura, a fim de criar melhorias ergonômicas futuras.

Autores como Kapandji (2000), lida (2005), Hall (2009), Hamill e Knutzen (2012) orientaram a análise das posturas e movimentos das articulações durante a realização da atividade de despenca desta pesquisa.

Para identificar as posturas do trabalhador durante a atividade de despenca, foi utilizado 0 sistema OWAS (Ovako Working Posture Analysing System). Esse sistema de registro postural foi desenvolvido em 1977 por três pesquisadores finlandeses (Karku, Kansi e Kuorinka), que encontraram 72 posturas típicas de trabalhadores da indústria pesada. Estas posturas resultaram diversas combinações de posições do dorso (4 posições), braços (3 posições) e pernas (7 posições). No sistema OWAS, as posturas são classificadas em: classe 1 (postura normal, que despensa cuidados); classe 2 (postura que deve ser verificada na próxima revisão rotineira), classe 3 (postura que merece atenção a curto prazo) e classe 4 (postura que merece atenção imediata). As classes das posturas estão retratadas na Tabela 1, que demonstra os resultados pela combinação das variáveis de dorso, braço e pernas (Tabela 1).

Tabela 1: Classificação das posturas no sistema OWAS conforme a combinação das variáveis

\begin{tabular}{|c|c|c|c|c|c|c|c|c|c|c|c|c|c|c|c|c|c|c|c|c|c|c|c|}
\hline \multirow[t]{2}{*}{ Dorso } & \multirow[t]{2}{*}{ Braços } & \multicolumn{3}{|c|}{1} & \multicolumn{3}{|c|}{2} & \multicolumn{3}{|c|}{3} & \multicolumn{3}{|c|}{4} & \multicolumn{3}{|c|}{5} & \multicolumn{3}{|c|}{6} & \multicolumn{3}{|c|}{7} & \multirow{2}{*}{$\begin{array}{l}\text { Pernas } \\
\text { Cargas }\end{array}$} \\
\hline & & 1 & 2 & 3 & 1 & 2 & 3 & 1 & 2 & 3 & 1 & 2 & 3 & 1 & 2 & 3 & 1 & 2 & 3 & 1 & 2 & 3 & \\
\hline \multirow[t]{3}{*}{1} & 1 & 1 & 1 & 1 & 1 & 1 & 1 & 1 & 1 & 1 & 2 & 2 & 2 & 2 & 2 & 2 & 1 & 1 & 1 & 1 & 1 & 1 & \\
\hline & 2 & 1 & 1 & 1 & 1 & 1 & 1 & 1 & 1 & 1 & 2 & 2 & 2 & 2 & 2 & 2 & 1 & 1 & 1 & 1 & 1 & 1 & \\
\hline & 3 & 1 & 1 & 1 & 1 & 1 & 1 & 1 & 1 & 1 & 2 & 2 & 3 & 2 & 2 & 3 & 1 & 1 & 1 & 1 & 1 & 2 & \\
\hline \multirow[t]{3}{*}{2} & 1 & 2 & 2 & 3 & 2 & 2 & 3 & 2 & 2 & 3 & 3 & 3 & 3 & 3 & 3 & 3 & 2 & 2 & 2 & 2 & 3 & 3 & \\
\hline & 2 & 2 & 2 & 3 & 2 & 2 & 3 & 2 & 3 & 3 & 3 & 4 & 4 & 3 & 4 & 4 & 3 & 3 & 4 & 2 & 3 & 4 & \\
\hline & 3 & 3 & 3 & 4 & 2 & 2 & 3 & 3 & 3 & 3 & 3 & 4 & 4 & 4 & 4 & 4 & 4 & 4 & 4 & 2 & 3 & 4 & \\
\hline \multirow[t]{3}{*}{3} & 1 & 1 & 1 & 1 & 1 & 1 & 1 & 1 & 1 & 2 & 3 & 3 & 3 & 4 & 4 & 4 & 1 & 1 & 1 & 1 & 1 & 1 & \\
\hline & 2 & 2 & 2 & 3 & 1 & 1 & 1 & 1 & 1 & 2 & 4 & 4 & 4 & 4 & 4 & 4 & 3 & 3 & 3 & 1 & 1 & 1 & \\
\hline & 3 & 2 & 2 & 3 & 1 & 1 & 1 & 2 & 3 & 3 & 4 & 4 & 4 & 4 & 4 & 4 & 4 & 4 & 4 & 1 & 1 & 1 & \\
\hline \multirow[t]{3}{*}{4} & 1 & 2 & 3 & 3 & 2 & 2 & 3 & 2 & 2 & 3 & 4 & 4 & 4 & 4 & 4 & 4 & 4 & 4 & 4 & 2 & 3 & 4 & \\
\hline & 2 & 3 & 3 & 4 & 2 & 3 & 4 & 3 & 3 & 4 & 4 & 4 & 4 & 4 & 4 & 4 & 4 & 4 & 4 & 2 & 3 & 4 & \\
\hline & 3 & 4 & 4 & 4 & 2 & 3 & 4 & 3 & 3 & 4 & 4 & 4 & 4 & 4 & 4 & 4 & 4 & 4 & 4 & 2 & 3 & 4 & \\
\hline \multirow{3}{*}{ Dorso } & \multicolumn{3}{|l|}{ 1. Reto } & \multirow{3}{*}{\multicolumn{2}{|c|}{ Braços }} & \multicolumn{5}{|c|}{ 1. Dois braços para baixo } & \multirow{3}{*}{\multicolumn{3}{|c|}{ Pernas }} & \multicolumn{5}{|c|}{ 1.Duas pernas retas } & \multicolumn{5}{|c|}{ 5. Uma perna ajoelhada } \\
\hline & \multicolumn{3}{|c|}{ 2. Inclinado } & & & \multicolumn{5}{|c|}{ 2.Um braço para cima } & & & & \multicolumn{5}{|c|}{$\begin{array}{l}\text { 2. Uma perna reta } \\
\text { 3. Duas pernas flexionadas }\end{array}$} & \multicolumn{5}{|c|}{ 6. Deslocamento com as pernas } \\
\hline & \multicolumn{3}{|c|}{ 3. Reto e torcido } & & & \multicolumn{5}{|c|}{ 3. Dois braços para cima } & & & & \multicolumn{5}{|c|}{$\begin{array}{l}\text { 3. Duas pernas flexionadas } \\
\text { 4. Uma perna flexionada }\end{array}$} & \multicolumn{5}{|c|}{ 7. Duas pernas suspensas } \\
\hline
\end{tabular}

Fonte: Próprios autores

\subsection{Coleta de dados}

A coleta de dados foi filmada em uma cooperativa produtora de bananas Cooper Rio Novo, em Corupá-SC. O sistema OWAS foi aplicado a partir das filmagens da tarefa, produzidas durante a coleta. Os tipos de bananas analisados na coleta correspondem a prata e caturra, também conhecida como nanica. 


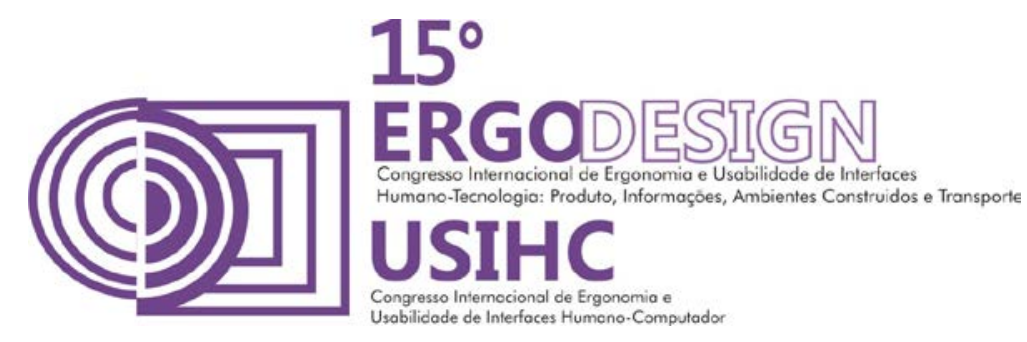

Os vídeos foram capturados em vista frontal, superior e lateral direita. Vale ressaltar que apenas um indivíduo masculino de participou da coleta, por ser o responsável pela tarefa de despenca na cooperativa produtora de bananas. Deste modo, este indivíduo fica encarregado de toda a produção e repete a tarefa de despenca várias vezes ao dia, o que por sua vez pode Ihe causar constrangimentos posturais e lesões por repetição.

\section{ANÁLISE DOS DADOS}

A seguir é apresentado a análise dos dados referentes a aplicação do sistema OWAS e estudo dos movimentos articulatórios do membro superior. A análise foi feita pela observação dos vídeos gerados na coleta, com velocidade reduzida 0,125 vezes, a fim de capturar melhor os movimentos das articulações do membro superior durante a atividade. O estudo tomou como base tanto a identificação postural, pelo sistema OWAS, como a análise dos movimentos das articulações do membro superior, que também interferem na atividade de despenca.

De modo geral, na etapa de despenca, o trabalhador se mantém de pé com o dorso inclinado e levemente torcido. $\mathrm{Na}$ maior parte do tempo os braços estão para baixo, em constante movimento, e eventualmente estes membros se posicionam para cima. Já as pernas ficam retas, no começo da atividade, e tendem a se flexionar para o corte das pencas inferiores. No decorrer da atividade, ocorre a flexão do punho (movimento que se aproxima as faces anteriores da mão e do antebraço) quando o usuário faz o corte de separação, e extensão do punho (movimento que aproxima as faces posteriores da mão e do antebraço) quando o punho volta para a posição normal de pega. Também nesta etapa, quando ocorre o corte da ráquis, 0 ombro rotaciona-se medialmente.

Para analisar melhor os movimentos em todas as fases do despencamento, dividiu-se esta tarefa em quatro partes que correspondem ao corte das pencas superiores, mediais, inferiores e restantes. Também foram feitas análises das articulações do membro superior por meio de ilustrações (Figura 2) que mostram de forma simples o funcionamento destas nas vistas: frontal, superior e lateral direita. Para ajudar a compreender os movimentos ilustrados, foi criada uma legenda com símbolos usados e seus respectivos significados, presentes na Figura 3.

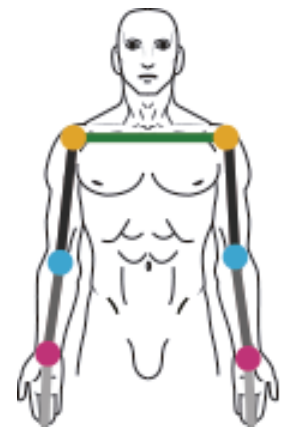

Figura 2: Ilustração das articulações do membro superior

Fonte: Próprios autores

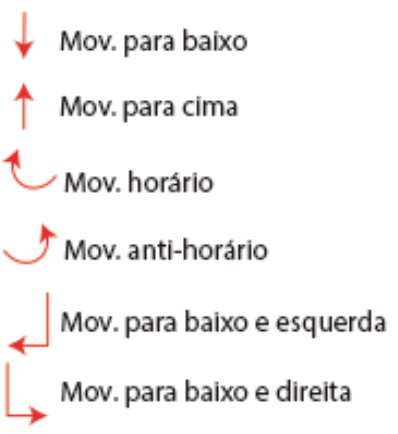

Figura 3: Símbolos usados nas ilustrações Fonte: Próprios autores 


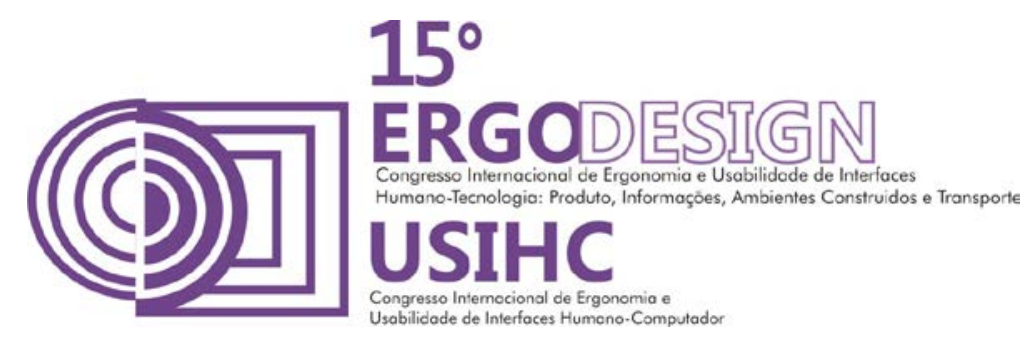

A primeira parte analisada compreende o corte das pencas superiores. Em relação a postura, o trabalhador nesta etapa apresenta o dorso levemente inclinado e torcido, um braço levantado e as duas pernas retas. Conforme a Tabela 1, supracitada, o corte das pencas superiores é classificado como de classe 3, ou seja, é uma postura que merece atenção a curto prazo.

Devido ao levantamento do membro superior que segura a ferramenta, as articulações do ombro, cotovelo e punho estão mais flexionadas que nos outros momentos da tarefa. $\mathrm{Na}$ despenca superior, ocorre a rotação medial do ombro, ou seja, o ombro faz o movimento de rotação para "dentro" no sentido horário. Já o cotovelo abaixa-se e movimenta-se em direção da parte posterior do corpo para fazer o corte da ráquis e volta lateralmente para a linha mediana, o que é denominado de adução. A articulação do punho também faz o movimento para baixo e termina a fase com a sua rotação no sentido horário. Os movimentos no despencamento de pencas superiores podem ser vistos na Figura 4 e sua análise ilustrada corresponde a Figura 5, que o mostra no plano frontal, superior e lateral direito.

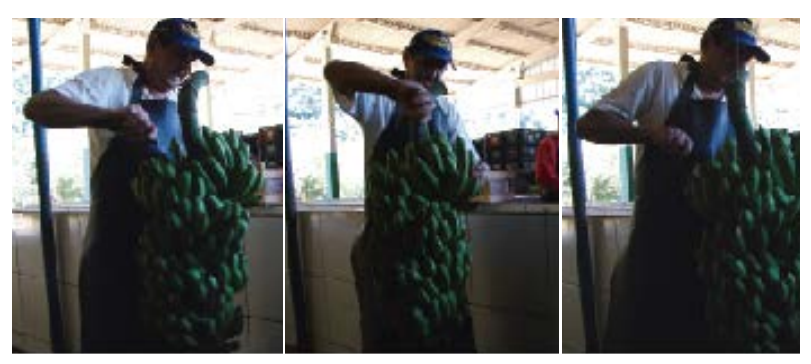

Figura 4: Movimentos da despenca das pencas superiores

Fonte: Próprios autores

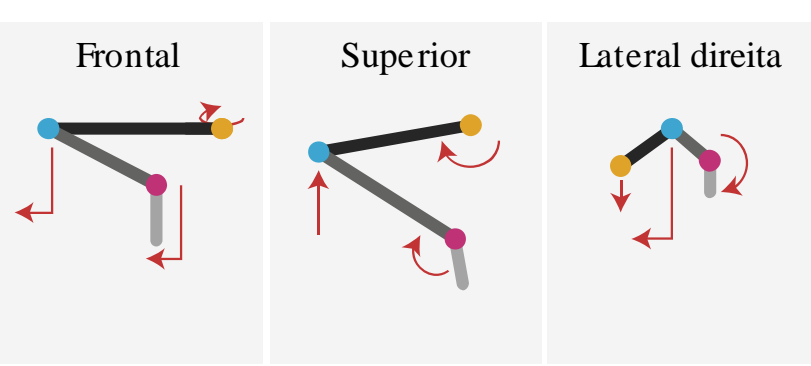

Figura 5: Análise dos movimentos no despencamento de pencas superiores nas vistas frontal, superior e lateral direita

Nas pencas do medianas, o usuário está em uma melhor posição para o corte da ráquis pois o membro superior que comanda a ferramenta consegue ter um alcance ótimo da penca, sem o excessivo levantamento ou abaixamento. Nesta postura, o trabalhador está com dorso inclinado e levemente torcido, os braços para baixo em movimento e as pernas levemente flexionadas. De acordo com o sistema OWAS, esta postura é de classe 2, ou seja, é uma postura de pouco risco que deve ser verificada em uma revisão futura da atividade.

No corte das pencas do meio, ocorre a rotação no sentido horário da articulação do ombro, rotação do cotovelo que também move-se para a parte posterior do corpo, rotação do cotovelo e rotação, flexão e extensão do punho. Os movimentos no despencamento de pencas mediais podem ser vistos na Figura 6 e sua análise corresponde a Figura 7, que o mostra no plano frontal, superior e lateral direito. 


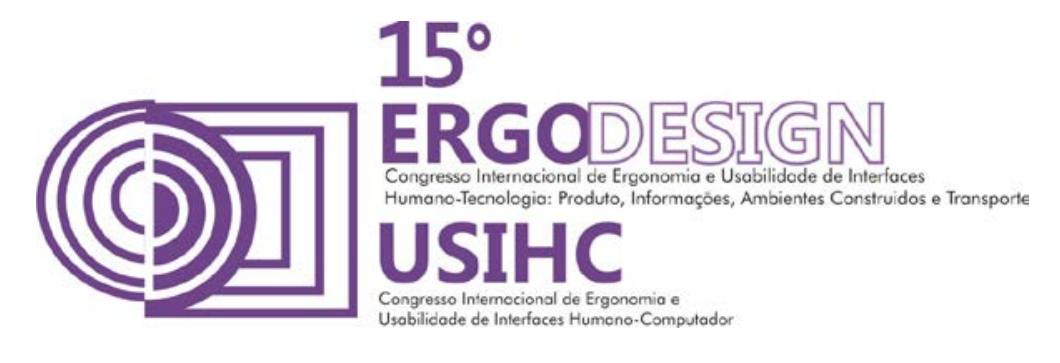

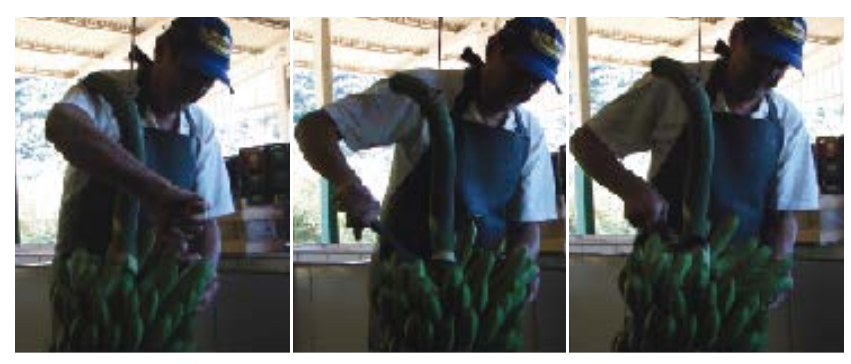

Figura 6: Movimentos da despenca das pencas mediais

Fonte: Próprios autores

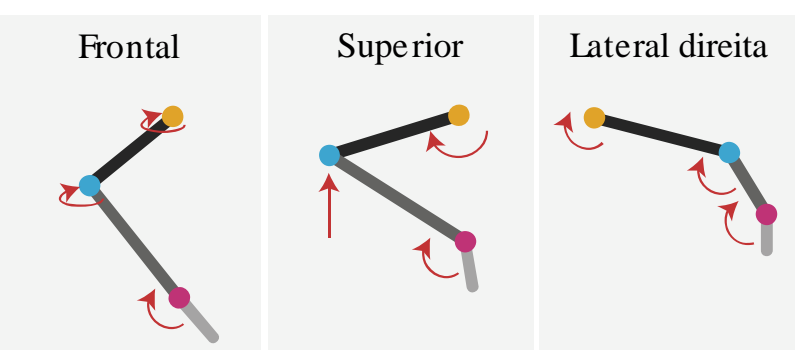

Figura 7: Análise dos movimentos no despencamento de pencas mediais nas vistas frontal, superior e lateral direita

Fonte: Próprios autores

Já nas pencas inferiores, o braço está mais esticado e o trabalhador necessita se abaixar, flexionando também o tronco e os joelhos para fazer o corte. Nesta fase, o trabalhador apresenta o dorso inclinado e torcido, os braços para baixo e as duas pernas flexionadas. De acordo com o sistema OWAS, esta postura é de classe 3 e merece atenção a curto prazo.

No corte das pencas inferiores ocorre a rotação no sentido horário da articulação do ombro, rotação do cotovelo e flexão e extensão do punho. Os movimentos no despencamento de pencas inferiores podem ser vistos na Figura 8 e sua análise corresponde a Figura 9, que 0 mostra no plano frontal, superior e lateral direito.

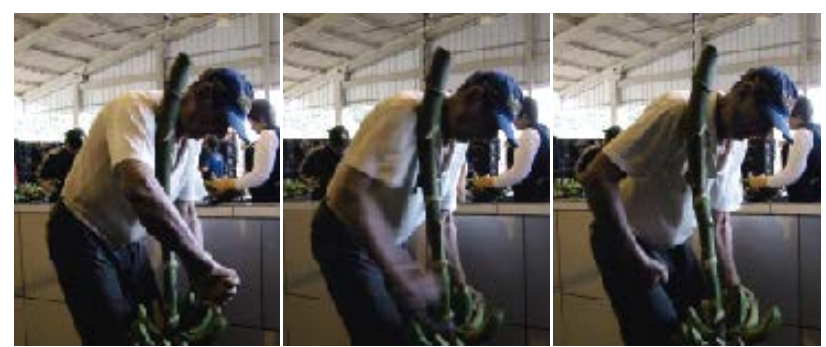

Figura 8: Movimentos da despenca das pencas inferiores

Fonte: Próprios autores

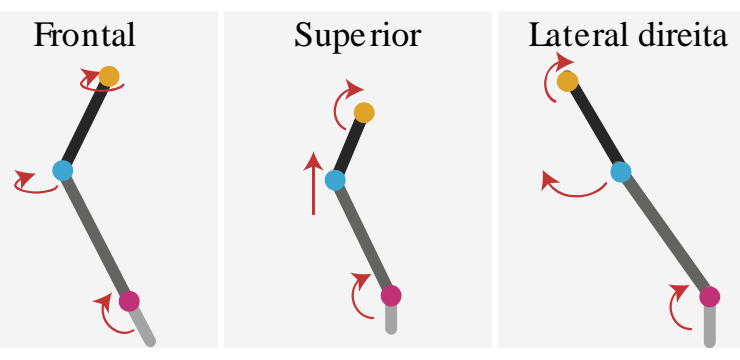

Figura 9: Análise dos movimentos no despencamento de pencas inferiores nas vistas frontal, superior e lateral direita

Fonte: Próprios autores

O corte das últimas pencas é feito de forma diferenciada das demais. O engaço é levado para perto do tanque de limpeza das bananas e a última penca é apoiada na borda deste para o seu corte, que é feito por baixo. A postura do trabalhador nesta fase apresenta dorso inclinado, um braço levantado e as duas pernas levemente flexionadas. Pelo sistema OWAS, esta posição é de classe 3 e merece vigilância. 


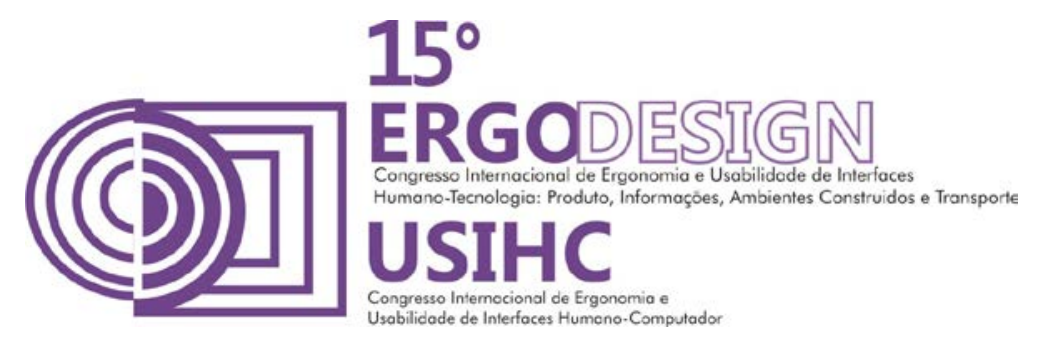

A separação da última penca ocorre com o movimento de adução do ombro, rotação do cotovelo e rotação, flexão e extensão do punho. Os movimentos no despencamento de pencas inferiores podem ser vistos na Figura 10 e sua análise corresponde a Figura 11, que o mostra no plano frontal, superior e lateral direito.

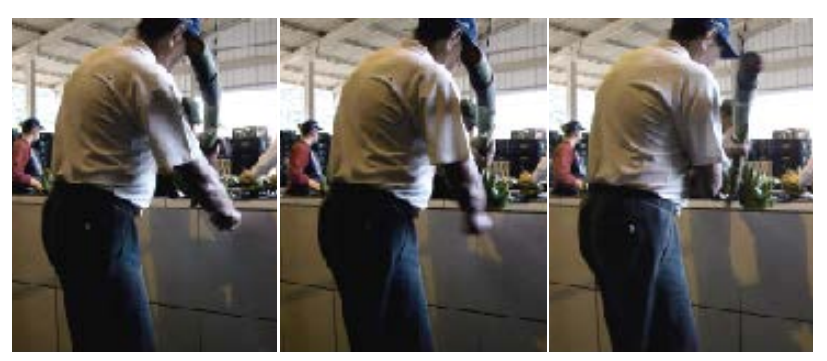

Figura 10: Movimentos da despenca das últimas pencas

Fonte: Próprios autores

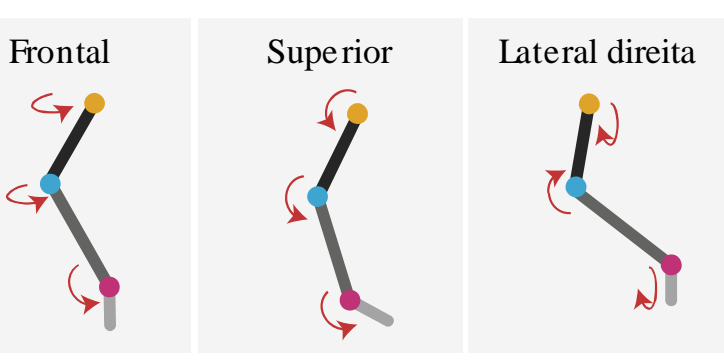

Figura 11: Análise dos movimentos no despencamento da última penca nas vistas frontal, superior e lateral direita

Fonte: Próprios autores

\section{RESULTADO}

O resultado da análise dos dados demonstrou que a atividade de despenca das bananas com a ferramenta utilizada provoca posturas inadequadas e excessivas torções, flexões e extensões das articulações do membro superior, pernas e dorso. Os cortes das pencas das extremidades foram os que apresentaram maior risco postural, com resultados de classe 3 no sistema OWAS, pelo levantamento e abaixamento descomedido do membro superior. Já nas pencas da extremidade inferior também notou-se a flexão do tronco e dos membros inferiores, com 0 objetivo o alcance da penca para o corte. Os frutos situados no meio possuíram um melhor aproveitamento do corte e posturas menos prejudiciais de classe 2, devido a posição do alcance do usuário quanto pelo tamanho da faca. Embora posturas mais agravantes, de classe 4, não tenham se mostrado presentes na análise, a repetição intensiva da tarefa tende a agravar as posturas de classe 3 e 2 .

As orientações relacionadas a postura foram delimitadas conforme a demanda da atividade, por meio de medidas antropométricas e recomendações ergonômicas apresentadas por lida (2005) e Dreyfuss (2005):

1. Recomenda-se que a despenca seja realizada em pé, pela maior mobilidade corporal que esta posição proporciona. Deste modo, os braços têm maior facilidade de alcançar comandos e realizar ações (IIDA, 2005).

2. Para evitar lesões, deve-se procurar manter a cabeça na posição vertical, fazer pequenas pausas de 2 a 10 segundos a cada 2 ou 3 minutos e limitar os movimentos repetitivos a 2000 por hora (IIDA, 2005).

3. Por fim, recomenda-se que o ângulo de conforto para o movimento circular do com o braço para frente seja de $45^{\circ}$ entre o engaço e mão do trabalhador, a para obter maior 


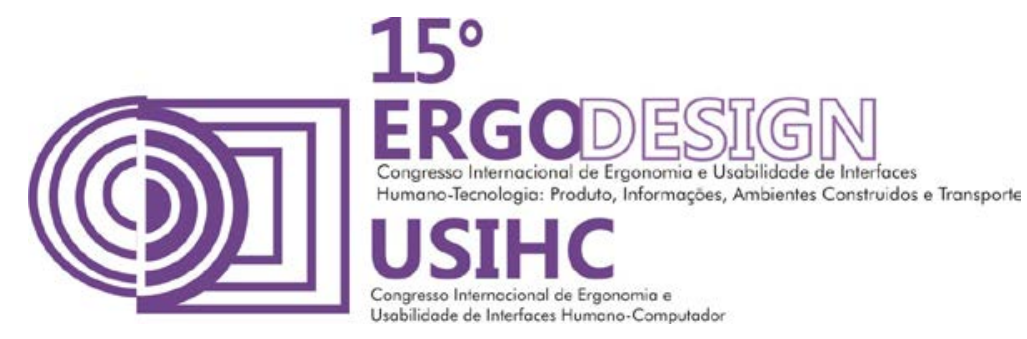

aproveitamento da força do trabalhador nesta posição e reduzir danos à saúde (DREYFUSS, 2005).

A partir do resultado da pesquisa, será possível criar requisitos para melhorar a postura do trabalhador através do redesign da ferramenta usada no despencamento, tendo em vista a redução da classificação das posturas de classe 3 para classe 1 (normal) ou classe 2 (com baixo risco); diminuição dos movimentos de flexão, extensão e rotação do membro superior, dorso e pernas; facilitação do acesso às pencas inferiores (redução inclinação do tronco); e facilitação do acesso às pencas superiores (redução do levantamento do braço).

\section{CONCLUSÃO}

A partir da análise da tarefa de despenca das bananas pelo sistema OWAS, observou-se que a atividade oferece grandes riscos posturais que merecem atenção. Na maior parte da atividade, o trabalhador está sujeito a constrangimentos posturais de classe 3 , que necessitam ser estudados para futuras aplicações de melhorias ergonômicas.

Observa-se que melhorias na ferramenta usada são essenciais para a redução dos riscos de constrangimentos posturais e lesões pela realização da tarefa. No entanto, além da ferramenta, outros fatores também influenciam na postura do trabalhador, como a altura das pencas das extremidades e o costume do trabalhador em projetar os mesmos movimentos para o corte das pencas, pois a velocidade da atividade e repetição dos movimentos agrava os riscos de constrangimentos posturais.

\section{REFERÊNCIAS BIBLIOGRÁFICAS}

ABRAHÃO, Roberto Funes; TERESO, Mauro José Andrade. Ergonomia e Agricultura. Disponível em: $<$ http://www.feagri.unicamp.br/unimac/pdfs/Ergonomia_e_Agricultura.pdf>. Acesso em: 16 out. 2014.

ARAGUAIA, Mariana. Banana. 2014. Disponível em: <http://www.brasilescola.com/frutas/banana.htm>. Acesso em: 13 ago. 2014.

BORGES, Ana Lúcia et al. Colheita e pós-colheita. Disponível em: $<$ http://sistemasdeproducao.cnptia.embrapa.br/FontesHTML/Banana/SistemaOrganicoCultivoBanana/colh eita.htm>. Acesso em: 04 dez. 2014.

DREYFUSS, Henry; TILLEY, Alvin R.. As medidas do homem e da mulher. Porto Alegre: Bookman, 2005.

EMBRAPA, Empresa Brasileira de Pesquisa Agropecuária / Centro Nacional de Pesquisa de Mandioca e Fruticultura Tropical. A cultura da banana. Brasília: Embrapa, 1998. 2. ed., revisada e aumentada.

EMBRAPA. Produção nacional de banana. 2013. Disponível em: <https://www.embrapa.br/documents/1355135/1905644/b1_banana.pdf/6c38c334-0fb6-4cd6-9fe343d2b1aada24>. Acesso em: 22 ago. 2014.

FLEMING, IVO. DIAGNÓSTICO ERGONÔMICO PRELIMINAR EM COMUNIDADE AGRÍCOLA COM PRODUÇÃo DIVERSIFICADA. 2003. 140 f. Dissertação (Mestrado) - Curso de Engenharia da Produção, 


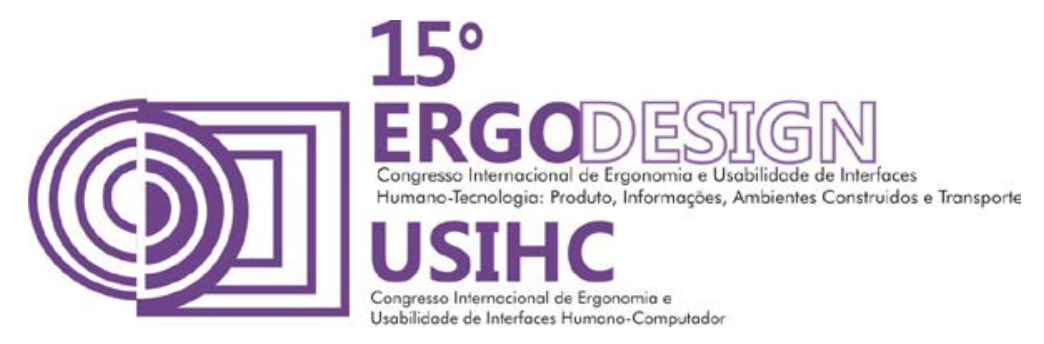

Departamento de Departamento de Engenharia de Produção e Sistemas, Universidade Federal de Santa Catarina, Florianópolis, 2003.

Food And Agriculture Organization Of The United Nations. BANANA MARKET REVIEW and BANANA STATISTICS 2012-2013. 2014. Disponível em: <http://www.fao.org/docrep/019/i3627e/i3627e.pdf>. Acesso em: 13 ago. 2014

HALL, Susan J.. Biomecânica Básica. 5. ed. Barueri: Manole, 2009.

HAMILL, Joseph; KNUTZEN, Kathleen M.. Bases Biomecânicas do Movimento Humano. 3. ed. Barueri: Manole, 2012.

IIDA, Itiro. Ergonomia: projeto e produção. 2. ed. rev. e ampl. São Paulo: Blucher, 2005.

International Ergonomics Association. Definition and Domains of ergonomics. Disponível em: <http://www.iea.cc/whats/index.html>. Acesso em: 09 jan. 2015.

KAPANDJI, Ibrahim Adalbert. Fisiologia articular, volume 1: esquemas comentados de mecânica humana. 5. ed. Rio de Janeiro: Editorial Médica Panamericana, 2000.

LEITE, Bruno Rangel Barbosa; CABRAL, Filipe Paes; SUETT, Waidson Bitão. IMPORTÂNCIA DA ERGONOMIA E SEGURANÇA DO TRABALHO NA MELHORIA DAS CONDIÇÕES DE TRABALHO DO TRABALHADOR CANAVIEIRO. Foz do Iguaçu: Enegep, 2007.

MONTEIRO, Janne C. O Processo de trabalho no desencadeamento dos agravos à saúde dos trabalhadores rurais: um estudo ergonômico na agricultura familiar em Santa Catarina. 2004. Tese (Doutorado em Engenharia de Produção e Sistemas - Área de Concentração: Ergonomia) - UFSC, Florianópolis.

Organização Internacional do Trabalho. OIT pede ação mundial urgente para combater doenças relacionadas com o trabalho. 2013. Disponível em: <http://www.oitbrasil.org.br/content/oit-pede-acaomundial-urgente-para-combater-doencas-relacionadas-com-o-trabalho>. Acesso em: 16 out. 2014.

SILVA NETO, Sebastião Pedro da; GUIMARÃES, Tadeu Graciolli. ADM65 - Evolução da cultura da banana no Brasil e no mundo. 2011. Disponível em: <http://www.cpac.embrapa.br/noticias/artigosmidia/publicados/287/>. Acesso em: 17 out. 2014.

\section{AGRADECIMENTOS}

A Coordenação de Aperfeiçoamento de Pessoal de Nível Superior (CAPES), ao Conselho Nacional de Desenvolvimento Científico e Tecnológico (CNPq), a Fundação de Amparo à Pesquisa e Inovação do Estado de Santa Catarina (FAPESC), a Empresa de Pesquisa Agropecuária e Extensão Rural de Santa Catarina (Epagri), a produtora de bananas Cooper Rio Novo de Corupá-SC e ao Núcleo de Gestão de Design da Universidade Federal de Santa Catarina (NGD/UFSC), que viabilizaram a pesquisa presente neste trabalho. 